\title{
DETEKSI CITRA GRANULOMA MELALUI RADIOGRAF PERIAPIKAL DENGAN METODE SCALE INVARIANT FEATURE TRANSFORM DAN KLASIFIKASI K-NEAREST NEIGHBOR
}

\author{
Siti Faradilla Zenda ${ }^{1}$, Bambang Hidayat ${ }^{2}$, Suhardjo ${ }^{3}$ \\ 1,2) Prodi S1 Teknik Telekomunikasi, Fakultas Teknik Elektro, Universitas Telkom Bandung \\ 3) Prodi S1 Kedokteran Gigi, Fakultas Kedokteran Gigi, Universitas Padjajaran Bandung \\ siti.zenda@gmail.com
}

\begin{abstract}
ABSTRAK
Radiograf periapikal merupakan komponen yang menghasilkan gambar radiografi dari gigi secara rinci dan jaringan apeks sekitarnya. Gambaran radiografi sangat membantu dokter gigi menegakkan diagnosis dan rencana perawatan kasus gigi impaksi. Dokter gigi mendiagnosa citra perapikal radiograf menggunakan mata namun karena keterbatasan indra penglihatan manusia bisa menyebabkan interpretasi masing-masing dokter gigi berbeda. Pada penelitian ini dibuatlah metode pengolahan citra yang dapat mendeteksi granuloma dari citra periapikal radiograf. Keluaran sistem dapat memberikan hasil yang dapat membantu dokter gigi dalam membuat keputusan dan meningkatkan diagnosis terhadap radiografi periapikal. Pada penelitian ini pembuatan sistem dilakukan dalam beberapa tahap yaitu pre-processing,ektraksi ciri dan klasifikasi. Metode yang akan digunakan dalam penelitian ini adalah Scale Invariant Feature Transformation (SIFT) sebagai metode ekstrasi ciri. SIFT adalah algoritma untuk mendeteksi dan menjelaskan fitur lokal pada citra. Proses klasifikasi menggunakan metode KNearest Neighbor (K-NN). K-NN adalah metode untuk mengklasifikasi obyek berdasarkan contoh latih terdekat. Hasil dari sistem ini adalah mampu untuk mengidentifikasi penyakit granuloma dengan akurasi 85,84\% dengan waktu komputasi rata-rata 4,04 detik.Katakunci: granuloma, radiografi periapikal, Scale Invariant Feature Transformation (SIFT), K-Nearest Neighbor (K-NN).
\end{abstract}

Keyword : Citra Granuloma, Radiograf Periapikal, Scale Invariant Feature Transform, K-Nearest Neighbor

\section{PENDAHULUAN}

Gigi merupakan salah satu organ yang sangat penting, oleh karna itu gigi perlu dirawat dengan baik. Penyakit dan kelainan pada gigi ada berbagai macam namun tidak semuanya dapat dideteksi tanpa bantuan teknologi. Salah satu cara untuk mendiagnosa penyakit gigi adalah dengan memanfaatkan citra dari hasil radiografi periapikal sehingga kelainan pada seluruh lapisan gigi dapat dilihat. Gambaran radiografi sangat membantu dokter gigi dalam menegakkan diagnosis dan rencana perawatan yang akan dilakukan. Kelainan pada gigi mempunyai bentuk radio lusen yang berbeda. Hasil diagnosis diinterpretasikan oleh dokter gigi dengan menggunakan mata. Diagnosa menggunakan mata bisa menyebabkan interpretasi dari tiap dokter gigi berbeda. Hal ini disebabkan kemampuan penglihatan manusia berbeda. Salah satu kelainan gigi yang dapat dilihat dari citra radiograf periapikal adalah granuloma.

Granuloma merupakan kelainan pada periapikal gigi akibat nekrotik. Granuloma merupakan kelainan pada gigi yang paling sering ditemukan pada pemeriksaan periapikal radiograf. Granuloma sangat sulit diketahui sehingga hanya bisa diketahui dengan pemeriksaan radiolusen. Seiring dengan perkembangan zaman maka teknologi harus juga harus berkembang tidak terkecuali dibidang radiologi. Diagnosis dengan menggunakan komputasi akan mempermudah dokter gigi dalam menegakkan diagnosis. Pada penelitian ini dibuat sistem yang mampu mendeteksi granuloma. Sistem ini dapat membantu dokter gigi untuk menegakkan dan meningkatkan akurasi diagnosis sehingga dapat melakukan perawatan yang sesuai dengan indikasi dari kasus . Pada penelitian ini, dibuat system yang dapat mendeteksi penyakit granuloma melalui citra periapical radiograph menggunakan metode Scale Invariant Feature Transformation (SIFT) untuk ekstraksi ciri dan k-Nearest Neighbor (k-NN) untuk proses klasifikasi. Sistem ini mampu mendeteksi penyakit granuloma secara langsung sehingga mampu membantu dokter dalam mendignosis hasil.

Tujuan yang ingin dicapai pada penelitian ini adalah :

1. Melakukan perancangan dan simulasi sistem yang dapat mendeteksi granuloma melalui citra radiograf periapikal.

2. Membuat suatu sistem yang mendeteksi penyakit granuloma dari hasil citra radiograf periapikal menggunakan metode SIFT dan klasifikasi K-NN .

3. Mengetahui parameter yang memberikan akurasi terbaik pada sistem deteksi granuloma.

4. Menganalisis performansi sistem berdasarkan hasil akurasi dan waktu komputasi yang diperoleh. 


\section{Perancangan sistem}

\subsection{Tahap Pre-processing}

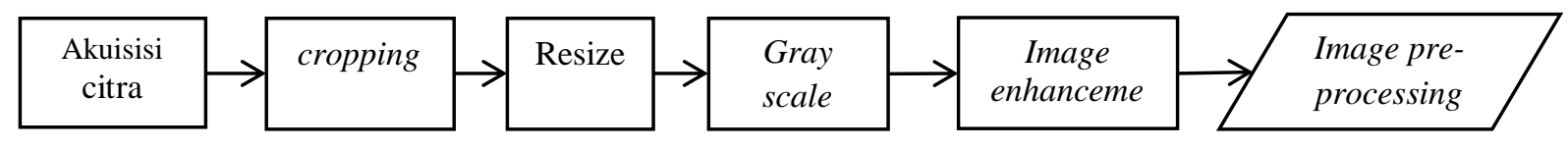

Gambar1. Blok diagram pre-processing

Citra periapikal radiograf terlebih dahulu discan sehingga berubah menjadi citra digital.Hasil dari citra yang didapatkan adalah keseluruhan bagian gigi. Bagian yang gigi yang dideteksi hanya pada ujung akar saja, oleh karena itu diperlukan cropping image.Citra masukan memiliki berbagai macam ukuran. Citra yang akan diproses harus mempunyai ukuran yang sama, oleh karena itu semua citra masukan harus di resize agar mempunyai ukuran yang sama. Setelah citra diresize selanjutnya adalah mengubah format citra dari RGB ke grayscale. Konversi ini akan mempermudah pendeteksian karna lebih sederhana dibandingkan dengan format RGB yang mempunyai 3 layer. Image enhancement pada penelitian dilakukan dengan 2 cara yaitu histogram equalization dan median filtering. Histogram equalization berfungsi untuk meningkatkan kualitas citra dengan suatu proses perataan histogram, dimana distribusi nilai derajat keabuan pada suatu citra dibuat rata. Median Filter merupakan salah satu teknik yang digunakan untuk menghilangkan noise, yaitu dengan memanfaatkan informasi dari urutan tingkatan data masukan [2].

\subsection{Ekstraksi Ciri Sift}

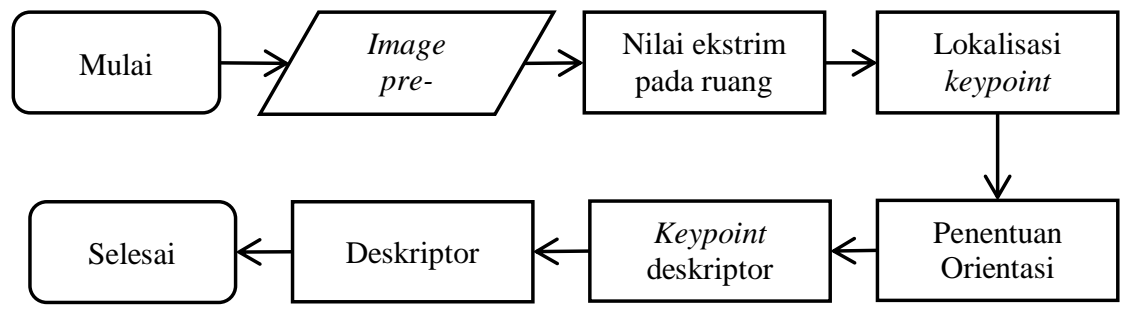

Gambar 2. Blok diagram ekstraksi ciri SIFT

1. Nilai ekstrim skala ruang

Tahap awal penentuan keypoint suatu citra adalah dengan mencari nilai ekstrim pada skala ruang. Caranya yaitu dengan menghitung lokasi dari titik yang invariant terhadap skala dan orientasi

$$
(x, y, \sigma)=(x, y, \sigma) *(x, y) \text {. }
$$

Keterangan :

$\mathrm{L}=$ fungsi DoG

$\mathrm{G}=$ Fungsi Gaussian $\mathrm{I}=$ citra

$\sigma=$ faktor skala ruang.

$$
G(x, y, \sigma)=\frac{1}{2 \pi \sigma^{2}} e^{-\frac{x^{2}+y^{2}}{\sigma^{2}}}
$$

Citra hasil Difference of Gaussian $\mathrm{D}(x, y, \sigma)$, diperoleh dengan konvolusi citra masukan dengan filter Differences of Gaussian maka:

$$
\begin{aligned}
D(x, y, \sigma) & =[G(x, y, k \sigma)-G(x, y, \sigma)-G(x, y, \sigma)] * I(x, y) \\
& =L(x, y, k \sigma)-L(x, y, \sigma)
\end{aligned}
$$

dengan mendeteksi maksima dan minimal dari sekumpulan citra Difference of Gaussian (DoG) yang diambil dalam beberapa skala ruang. Dengan menggunakan fungsi Gaussian [3]:

Dimana * merupakan operasi konvolusi dalam $\mathrm{x}$ dan $\mathrm{y}, \mathrm{I}(\mathrm{x}, \mathrm{y})$ merupakan citra masukan dan fungsi Gaussiannya adalah 
Setelah citra hasil DoG didapatkan pada setiap oktaf, maka langkah selanjutnya adalah mencari kandidat keypoint. Untuk mendapatkan nilai maksimum atau minimum lokal maka masingmasing piksel pada citra hasil DoG akan dibandingkan dengan 8 piksel disekitarnya yang berada pada skala yang sama dan dengan 9 piksel yang bersesuaian dengannya pada skala. Jika piksel tersebut merupakan maksimum atau minimum lokal, maka piksel tersebut akan dijadikan sebagai kandidat keypoint.

\section{Menentukan Keypoint}

Kandidat keypoint yang memiliki nilai kontras yang rendah (sensitif terhdapa noise), kandidat keypoint yang kurang jelas dan terletak disepanjang tepi akan dihilangkan. Mengeliminasi keypoint yang memiliki kontras rendah dapat menggunakan formula ekspansi Taylor. Keypoint yang dieliminasi dengan menggunakan pekthreshold yang telah ditentukan yaitu 0,03. Jika nilai keypoint kurang dari threshold maka keypoint akan dieliminasi. Untuk menghilangkan keypoint yang berada pada sekitar garis tepi maka digunakan persamaan matriks Hessian 2x2[2].

$$
\frac{\operatorname{Tr}(H)^{2}}{\operatorname{Det}(H)}<\frac{(r+1)^{2}}{r}
$$

Keterangan :

$\mathrm{T}=$ trace dari matriks Hessian,

Det $=$ determinan dari matrks Hessian,

$\mathrm{r}=$ threshold

Nilai $r$ yang digunakan adalah $r=10$, jika keypoint memiliki nilai lebih tinggi dari 10 maka keypoint tersebut akan dihilangkan.

\section{Penentuan Orientasi}

Penentuan orientasi dilakukan dengan cara perhitungan nilai gradient magnitude (2.8) dan sudut orientasi yang terbentuk (2.9). Pada masing-masing keypoint akan diberi orientasi berdasarkan sifat lokal-lokal pada citra. Dengan penentuan orientasi maka nilai maka keypoint yang dihasilkan tidak berpengaruh terhadap adanya variasi rotasi citra[3].

$$
m(x, y)=\sqrt{(L(x+1, y)-L(X-1, Y))^{2}+(L(x, y+1)-L(x, y-1))^{2}} .
$$

Keterangan :

$\mathrm{m}=$ nilai magnitude/bobot,

$\mathrm{L}=$ citra hasil konvolusi gaussian,

$\mathrm{x}, \mathrm{y}=$ koordinat

$$
\theta(x, y)=\tan ^{-1} \frac{L(x, y+1)-L(x, y-1)}{L(x+1, y)-L(x-1, y)}
$$

Keterangan :

$\theta=$ nilai orientasi

$\mathrm{L}=$ citra hasil konvolusi gaussian

$\mathrm{x}, \mathrm{y}=$ koordinat

\section{Deskriptor Keypoint}

Tahap ini keypoint yang telah diorientasikan akan diberikan pencirian khusus dengan cara menghitung ciri yang benar-benar membedakan suatu citra seperti perubahan intensitas cahaya atau sudut pandang 3D. Dari perhitungan besar gradient magnitude dan sudut orientasi diperoleh daerah cakupan yang dibatasi oleh jendela Gaussian, direpresentasikan dalam bentuk lingkaran. Dari perhitungan gradien magnitude dan orientasi tersebut akan didapatkan sebuah array berukuran $4 \times 4$ dengan 8 orientasi. Maka dari itu, akan digunakan $4 \times 4 \times 8=128$ buah vektor pada setiap keypoint[4]. 


\subsection{K-Nearest Neighbor}

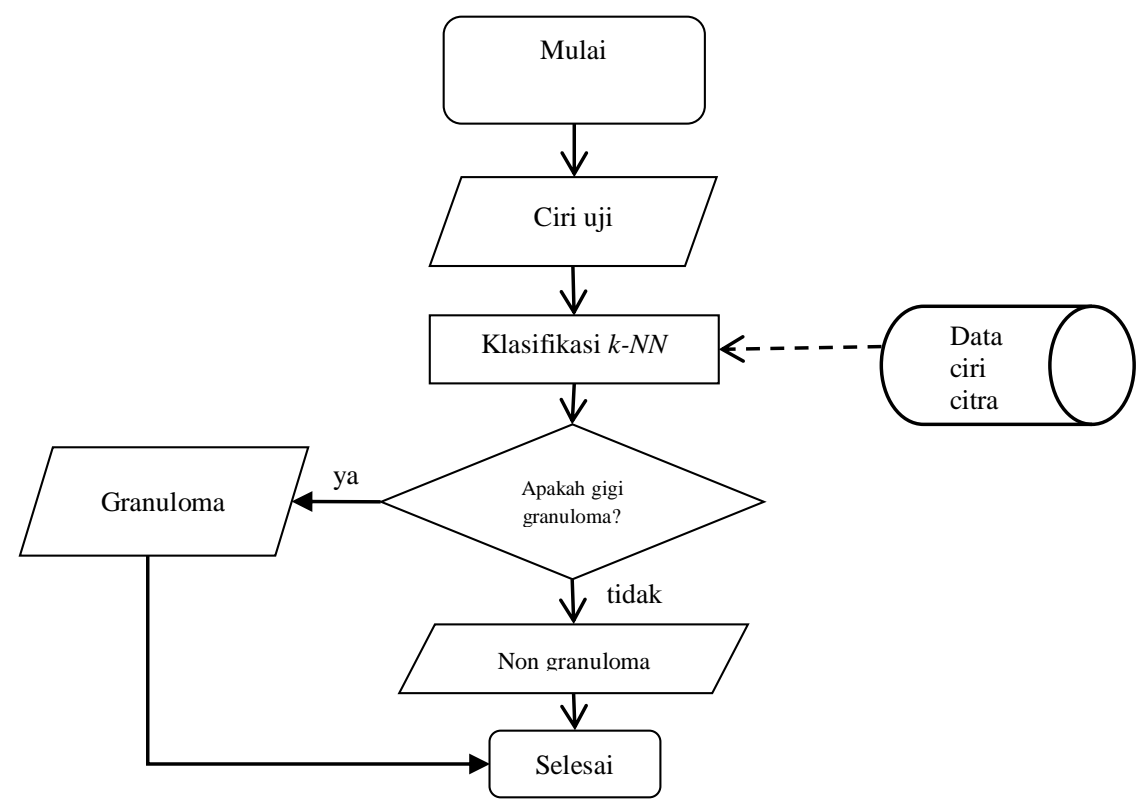

Gambar 3. Blok diagram klasifikasi k-NN

Penelitian ini mengelompokkan data uji $\mathrm{k}$ Nearest Neighbor dengan menghitung jarak, yaitu : euclidean dan city block. Untuk menentukan pengelompokannya k - Nearest Neighbor perlu memperhatikan jumlah tetangganya atau jumlah $\mathrm{k}$. Klasifikasi per kelas didasarkan pada jarak
Euclidean atau cityblock yang dihasilkan tiap ciri dari citra uji terhadap database citra latih.

1. Euclidean distance

Euclidean distance menghitung akar kuadrat perbedaan dua vector, rumusnya yaitu[5]:

$$
E U D(p, q)=\sqrt{\sum(p i-q i)^{2}}
$$

\section{City Block}

City Block distance atau Manhatan distance yaitu menghitung jarak tetangga dengan cara menghitung perbedaan nilai absolut dari dua vector. Rumusnya yaitu[5] :

$$
(p, q)=\Sigma|p i-q i|
$$

\subsection{Performansi Sistem}

1. Tingkat Akurasi

Akurasi merupakan ukuran ketepatan sistem dalam mengenali masukan yang diberikan sehingga menghasilkan keluaran yang benar. Secara matematis dapat dituliskan sebagai berikut:

$$
\text { Akurasi }=\frac{\text { Jumlah data benar }}{\text { Jumlah data keseluruhan }} \times 100 \%
$$

2. Waktu Komputasi

Waktu komputasi adalah waktu yang dibutuhkan sistem untuk melakukan suatu proses.

Waktu komputasi $=$ Waktu selesai - waktu mulai. 


\section{Pengujian dan Analisis Sistem}

Pada pengujian sistem dibagi menjadi dua kelompok data yaitu :

1. Pengujian dengan menggunakan data gigi nomor sama yaitu gigi nomor 2-1.

Data latih : 5 citra diagnosis granuloma dan 5 citra diagnosis nongranuloma

Data uji : 6 citra diagnosis granuloma dan 6 citra diagnosis nongranuloma

2. Pengujian dengan menggunakan data gigi nomor random.

Data latih: 7 citra diagnosis granuloma dan 7 citra diagnosis nongranuloma

Data uji : 10 citra diagnosis granuloma dan 10 citra diagnosis nongranuloma

\subsection{Pengaruh nilai resize dan Image} Enhancement terhadap performansi sistem

Pengujian ini dilakukan pada tahap preprocessing yaitu pada tahap resize citra dan penambahan median filtering. Pada pengujian ini akan diambil 3 nilai size yang berbeda yaitu 32×32, $64 \times 64,128 \times 128$. Pada tahap ini juga dilakukan pada tahap image enhancement yaitu dengan membandingkan akurasi dan waktu komputasi ketika penambahan median filtering dengan histogram equlization dan hanya menggunakan histogram equlization saja. Pada proses ektraksi ciri digunakan nilai peakthreshold 0.03 dan pada saat klasifikasi digunakan nilai $\mathrm{k}=1$ dengan perhitungan cityblock. Tabel 1. merupakan hasil pengujian pada nomor gigi sama.

Tabel 1. Pengaruh resize dan image enhancement pada citra gigi nomor 2-1

\begin{tabular}{|c|c|c|c|c|c|c|}
\hline \multirow{2}{*}{ Ukuran citra } & \multicolumn{3}{|c|}{ Tanpa Median Filtering } & \multicolumn{3}{c|}{ Menggunakan Median Filtering } \\
\cline { 2 - 7 } & Akurasi & $\begin{array}{c}\text { Waktu } \\
\text { Komputasi(s) }\end{array}$ & $\begin{array}{c}\text { Jumlah } \\
\text { Benar }\end{array}$ & Akurasi & $\begin{array}{c}\text { Waktu } \\
\text { Komputasi(s) }\end{array}$ & $\begin{array}{c}\text { Jumlah } \\
\text { Benar }\end{array}$ \\
\hline 32 X 32 & 91,67 & 3,96 & 11 & 75,00 & 4,31 & 9 \\
\hline 64 X 64 & 58,33 & 9,94 & 7 & 50,00 & 9,07 & 6 \\
\hline $128 \times 128$ & 58,33 & 37,48 & 7 & 50,00 & 32,61 & 6 \\
\hline
\end{tabular}

Tabel1. diatas menunjukkan bahwa perubahan resize citra berpengaruh terhadap performansi tingkat akurasi dan waktu komputasi. Dapat dilihat bahwa ukuran resize yang memiliki tingkat akurasi paling baik adalah ukuran 32x32 dan yang paling kecil adalah resize ukuran $128 \times 128$. Pada pengujian pertama didapatkan performansi sistem pada gigi nomor sama yang paling baik adalah menggunakan resize ukuran 32x32 tanpa menggunakan median filtering dengan hasil akurasi sistem yaitu 91,67\%, waktu komputasi rata-rata 3,96 detik dan jumlah data benar adalah 11 citra dari 12 data uji.Berdasarkan percobaan didapatkan bahwa ukuran resize yang semakin besar akan memperkecil akurasi sistem dan waktu komputasi yang lebih lama.

Hasil pengujian menunjukkan bahwa akurasi paling baik didapatkan tanpa penambahan median filtering. Penyebab menurunnya akurasi dengan menambah median filtering karena sifatnya mengganti nilai pixel utama dengan nilai tengah pixel sekitarnya, sedangkan pada ekstraksi ciri SIFT kandidat keypoint merupakan pixel yang memiliki nilai maximum atau minimum. Maka dengan menambah median filtering bisa menyebabkan piksel yang diganti merupakan kandidat keypoint. Waktu komputasi yang terbaik juga didapatkan tanpa menggunakan median filtering.

Tabel 2. Pengaruh resize dan image enhancement citra gigi nomor random

\begin{tabular}{|c|c|c|c|c|c|c|}
\hline \multirow{2}{*}{ Ukuran citra } & \multicolumn{3}{|c|}{ Tanpa Median Filtering } & \multicolumn{3}{c|}{ Menggunakan Median Filtering } \\
\cline { 2 - 7 } & Akurasi & $\begin{array}{c}\text { Waktu } \\
\text { Komputasi(s) }\end{array}$ & $\begin{array}{c}\text { Jumlah } \\
\text { Benar }\end{array}$ & Akurasi & $\begin{array}{c}\text { Waktu } \\
\text { Komputasi(s) }\end{array}$ & $\begin{array}{c}\text { Jumlah } \\
\text { Benar }\end{array}$ \\
\hline 32 X 32 & 75 & 4,197 & 15 & 60 & 3,27 & 12 \\
\hline 64 X 64 & 70 & 11,43 & 14 & 55 & 7,46 & 11 \\
\hline 128 X 128 & 50 & 28,97 & 10 & 55 & 25,55 & 11 \\
\hline
\end{tabular}

Dapat dilihat pada tabel diatas bahwa ukuran resize pada pengujian citra random juga mempengaruhi performansi sistem. Performansi yang paling baik juga didaptkan pada ukuran resize $32 \times 32$ dan yang paling rendah adalah ukuran resize $128 \times 128$. Sedangkan penambahan median filtering juga mempengaruhi performansi sistem. Ukuran resize yang kecil akan membuat jarak antar kelas semakin jauh, sedangkan ukuran size yang lebih besar jarak antar kelas semakin dekat .

Hasil terbaik yang didapatkan yaitu akurasi sistem $75 \%$, waktu komputasi rata-rata 3,63 detik dengan jumlah data benar 15 citra dari 20 data uji. Dari tabel 1. dan tabel 2. dapat dilihat bahwa waktu komputasi akan semakin lama ketika ukuran resize semakin besar, hal ini disebabkan karena pencarian 
keypoint akan semakin banyak ketika ukuran pixel juga meningkat.

\subsection{Pengaruh nilai peakthreshold terhadap performansi sistem}

Pengujian yang kedua ini dilakukan pada tahap ekstraksi ciri. Disini dilihat bagaimana pengaruh nilai peakthreshold terhadap persentase akurasi dan waktu komputasi. Peakthreshold tejadi pada proses keypoint localization pada SIFT. Pada proses ini akan terjadi eliminasi kandidat keypoint yang memiliki kontras rendah. Nilai peaktrheshold yang digunakan yaitu 0.03, 0.06 dan 0.09. Pada pengujian pertama didapatkan parameter terbaik yaitu nilai resize 32x32 dan menggunakan image enhancement hanya dengan ekualisasi histogram. Pada klasifikasinya digunakan $\mathrm{k}-\mathrm{NN}$ dengan nilai $\mathrm{k}=1$ dengan menggunakan cityblock.

Tabel 3. Hasil pengujian skenario kedua pada nomor gigi sama

\begin{tabular}{|c|c|c|c|}
\hline Nilai Peakthreshold & Akurasi & Waktu Komputasi(s) & Jumlah Benar \\
\hline 0,03 & 91,67 & 4,20 & 11 \\
\hline 0,06 & 58,33 & 3,15 & 8 \\
\hline 0,09 & 25,00 & 2,77 & 3 \\
\hline
\end{tabular}

Dapat dilihat pada tabel diatas bahwa nilai peakthreshold mempengaruhi nilai akurasi sistem. Nilai peakthreshold yang memiliki akurasi paling baik adalah 0.03 dengan akurasi $91,67 \%$ dan yang paling buruk adalah 0.09 dengan akurasi 25\%, sehingga peningkatan nilai threshold akan memperburuk hasil akurasi sistem. Sedangkan pada waktu komputasi berbanding terbalik dengan akurasi, waktu komputasi yang paling baik adalah pada threshold 0.09 dan yang paling lama adalah 0,03 .

Tabel 4. Hasil pengujian skenario kedua pada nomor gigi random

\begin{tabular}{|c|c|c|c|}
\hline Peakthreshold & Akurasi & Waktu Komputasi(s) & Jumlah Benar \\
\hline 0,03 & 75 & 3,525734792 & 15 \\
\hline 0,06 & 70 & 3,048209034 & 14 \\
\hline 0,09 & 60 & 2,703159172 & 12 \\
\hline
\end{tabular}

Pada tabel 4. diatas hasil pengujian pada gigi nomor random juga memiliki hasil yang sama seperti gigi nomor sama. Nilai akurasi paling tinggi adalah $75 \%$ dengan threshold 0.03 dan akurasi paling rendah adalah $60 \%$, maka pada gigi nomor random kenaikan nilai threshold juga menurunkan akurasi sistem. Hal ini disebabkan karena banyaknya keypoint yang hilang, padahal keypoint tersebut memiliki informasi yang cukup untuk kemudian dibandingkan dengan data latih. Waktu komputasi juga sama seperti gigi nomor sama dimana waktu komputasi paling baik pada threshold 0.09 dan yang paling rendah adalah 0.03.

\subsection{Pengaruh Nilai K dan Perhitungan K-NN terhadap performansi sistem}

Penguijian ini dilakukan pada proses klasifikasi yaitu dengan menguji akurasi dan waktu komputasi ketika menggunakan euclidean dan cityblock. Nilai k pada klasifikasi juga dirubah yaitu dengan nilai $1,3,5,7$. Pada tahap preprocessing digunakan resize $32 \times 32$ dan menggunakan ekualisasi histogram. Pada ektraksi ciri digunakan peakthreshold 0.03. Berikut merupakan hasil pengujian ketiga pada gigi nomor sama(2-1).

Tabel 5. Pengaruh nilai $\mathrm{k}$ dan perhitungan K-NN pada gigi nomor 2-1

\begin{tabular}{|c|c|c|c|c|c|c|}
\hline \multirow{2}{*}{ Nilai k } & \multicolumn{3}{|c|}{ Euclidean } & \multicolumn{3}{c|}{ Cityblock } \\
\cline { 2 - 7 } & Akurasi & $\begin{array}{c}\text { Waktu } \\
\text { komputasi(s) }\end{array}$ & $\begin{array}{c}\text { Jumlah } \\
\text { Benar }\end{array}$ & Akurasi & $\begin{array}{c}\text { Waktu } \\
\text { komputasi(s) }\end{array}$ & $\begin{array}{c}\text { Jumlah } \\
\text { Benar }\end{array}$ \\
\hline 1 & 66,67 & 4,08 & 8 & 91,67 & 4,20 & 11 \\
\hline 3 & 83,33 & 4,32 & 10 & 83,33 & 4,07 & 10 \\
\hline 5 & 83,33 & 4,02 & 10 & 83,33 & 4,04 & 10 \\
\hline 7 & 83,33 & 4,49 & 10 & 83,33 & 4,01 & 10 \\
\hline
\end{tabular}

Akurasi yang dihasilkan dapat dilihat bahwa yang paling baik adalah menggunakan cityblock dengan akurasi maksimal sebesar 91,67\% sedangkan dengan menggunakan euclidean didapatkan akurasi maksimal sebesar 83,33\%.
Dapat dilihat tabel 4.5 pada nilai $\mathrm{k}=1$ dengan cityblock memberikan akurasi 91,67\% sedangkan nilai $\mathrm{k}=3, \mathrm{k}=5, \mathrm{k}=7$ memiliki akurasi lebih rendah dengan nilai yang sama yaitu $83,33 \%$. Nilai $k=1$ menggunakan euclidean mendapatkan akurasi 
paling rendah yaitu pada $\mathrm{k}=1$ dengan akurasi $66,67 \%$. Performansi paling tinggi yaitu $83,33 \%$ pada perhitungan euclidean didapat dengan $\mathrm{k}=3, \mathrm{k}=5, \mathrm{k}=7$.

Tabel 6. Pengaruh nilai k dan perhitungan K-NN pada gigi nomor random

\begin{tabular}{|c|c|c|c|c|c|c|}
\hline \multirow{2}{*}{ Nilai k } & \multicolumn{3}{|c|}{ Euclidean } & \multicolumn{3}{c|}{ Cityblock } \\
\cline { 2 - 7 } & Akurasi & $\begin{array}{c}\text { Waktu } \\
\text { komputasi(s) }\end{array}$ & $\begin{array}{c}\text { Jumlah } \\
\text { Benar }\end{array}$ & Akurasi & $\begin{array}{c}\text { Waktu } \\
\text { komputasi(s) }\end{array}$ & $\begin{array}{c}\text { Jumlah } \\
\text { Benar }\end{array}$ \\
\hline 1 & 70 & 4,87 & 14 & 75 & 3,52 & 15 \\
\hline 3 & 80 & 5,03 & 16 & 80 & 4,30 & 16 \\
\hline 5 & 80 & 4,20 & 16 & 80 & 4,36 & 16 \\
\hline 7 & 80 & 3,88 & 16 & 75 & 4,39 & 15 \\
\hline
\end{tabular}

Pada gigi nomor random euclidean dan cityblock memiliki persentasi akurasi maksimal yang sama yaitu $80 \%$. Waktu komputasi yang terbaik pada euclidean dengan nilai 3,8878488 detik. Nilai $\mathrm{k}$ mempengaruhi akurasi sistem dengan nilai maksimal $80 \%$ pada $\mathrm{k}=3, \mathrm{k}=5, \mathrm{k}=7$ pada perhitungan euclidean dan $\mathrm{k}=3, \mathrm{k}=5$ pada perhitungan cityblock.

\section{Kesimpulan}

Setelah perancangan dan implementasi terlaksana maka dapat disimpulkan bahwa implementasi pengolahan citra radiograf periapikal menggunakan metode SIFT dan k-NN berhasil dilakukan. Sistem ini berguna untuk mendeteksi granuloma pada citra radiografi periapikal. Sistem memiliki akurasi rata-raat $85,84 \%$ dengan waktu komputasi rata-rata 4,04 detik. parameter yang memberikan performansi terbaik pada tahap preprocessing adalah resize dengan ukuran $32 \times 32$ dan menggunakan histogram equalization. Performansi terbaik pada tahap ekstraksi ciri SIFT adalah peakthreshold dengan nilai 0,03. Performansi terbaik pada klasifikasi terdapat pada nilai $\mathrm{k}=1$ dengan perhitungan euclidean untuk gigi nomor2-1. Performansi terbaik pada gigi nomor random didapatkan pada klasifikasi $\mathrm{k}=7$ dengan perhitungan cityblock.

\section{Daftar Pustaka}

[1]. A.Sebastian, P. Panikar, K. Kota dan A. Sasi, "Periapical Granuloma," International Journal of Preventive and Clinical Dental Research, vol. 1,2016
[2]. B. Yuwono, "Image Smoothing Menggunakan Mean Filtering, Median Filtering dan Gaussian Filtering," TELEMATIKA, 2010

[3]. D. G. Lowe, "Distinctive Image Features," January 2004

[4]. C. N. Santri, "Mengubah Citra Berwarna Menjadi GrayScale," vol. 16, p. 14, Januari 2011

[5]. J. W. Williams dan Y. Li, "Comparative Study of Distance Functions for Nearest Neighbor," Advance Techniques in Computing Sciences and Software Engineering, 2010

[6]. A. Gupta, "Intra Oral Periapical Radiographybasics yet intrigue:A Review," Bangladesh Jurnal of Dental Research \& Education, vol. 04, 2014

[7]. D. G. Lowe, "Local Feature View Clustering for 3D Object Recognition," December 2001

[8]. M. H. Purnomo dan A. Muntasa, Konsep Pengolahan Citra Digital dan Ekstraksi Fitur, 1st penyunt., Yogyakarta: Graha Ilmu, 2014

[9]. M. Rahman, Sistem Identifikasi Telinga Menggunakan Scale Invariant Feature, Bandung, 2014

[10]. F. L.R.G dan D. P.M.H, "Periapical Radiographic Techniques during Endodontic Diagnosis," vol. 30, p. 251, 1997

[11]. N. Ahmad dan A. Hadinegoro, "Metode Histogram Equalization Untuk Perbaikan Citra Digital," Seminar Nasional Teknologi Informasi \& Komunikasi Terapan, 2012

[12]. A. G. Ramadhan, Serba Serbi Kesehatan Gigi dan Mulut, Jakarta: Bukune, 2010 